\title{
The effects of combined aerobic and resistance training on inflammatory markers in obese men
}

\author{
Chan-Ho Jin', Hyun-Seung Rhyu², Joo Young Kim ${ }^{3, *}$ \\ 'Department of Hotel, Casino and Tourism, Hanseo University, Seosan, Korea \\ ${ }^{2}$ Department of Physical Education, Jungwon University, Goesan, Korea \\ ${ }^{3}$ Graduate School of Pharmaceutical Sciences, Ewha Womans University, Seoul, Korea
}

It is important to treat obesity and the related noncommunicable diseases. The main objective of this study is the effect of different training types on inflammatory and immune markers in obesity. Seventeen obese men with body mass index $(\mathrm{BMI}) \geq 26 \mathrm{~kg} / \mathrm{m}^{2}$ were randomly divided into two groups: aerobic training group $(A T ; n=9)$ and combined aerobic and resistance training group (CT; $n=8)$. Body composition (weight, $\mathrm{BMI}, \%$ body fat), factors of physical performance (one-repetition maximum [1RM], maximal oxygen uptake $\left[\mathrm{VO}_{2 \max }\right]$ ), inflammatory markers (interleukin-6, tumor necrosis factor-alpha [TNF- $\alpha$ ]), immune markers (leukocyte, natural killer cell) were analyzed before and after 8-week training. Body composition (weight, BMI, and \%body fat) was significantly reduced after training in both the AT and CT groups $(P<0.05)$. As a result of training, $\mathrm{VO}_{2 \max }$ of all training groups was increased and 1RM of CT group was partially improved. In particular, the inflammatory marker, TNF- $\alpha$ was significantly reduced $(P<0.05)$ and the change was correlated with \%body fat in the posttraining CT group. In this study, we found that combined training for 8 weeks improved physical fitness, body composition, and inflammation. It is suggested that restoring obesity through combined training of aerobic and resistance exercise is related to changes in serum TNF- $\alpha$ levels.

Keywords: Aerobic training, Obesity, \%Body fat, Resistance training, Tumor necrosis factor-alpha

\section{INTRODUCTION}

The World Health Organization (WHO) reported in 2016 that $39 \%$ of adults over the age of 18 are overweight and $13 \%$ obese in the world and that these numbers are nearly three times as high as those in 1975 (World Health Organization, 2017). Obesity is a state of unnecessary fat is accumulating in the body, and the disease state can be caused by complex factors including life habits related to the imbalance of energy intake and consumption, diet, and physical activities (Goran, 2000). Obesity is a metabolic disorder and has the main risk factors for several other diseases, such as cardiovascular diseases, diabetes, a later onset of asthma, a certain type of cancers, and inflammatory diseases. In adipose tissue of obese people, inflammation-related factors, as well as adipocytes, are increased. Pro-inflammatory cytokines such as interleu- kin (IL)-1, IL-6 and tumor necrosis factor-alpha (TNF- $\alpha$ ) are followed by an increase in the infiltration of the immune cell phenotypes that cause inflammation in adipose tissues. In particular, macrophages in adipose tissue are shift from M2 to M1 phenotypes during obesity (Kim et al., 2015).

It is not yet clear how the state of chronic inflammation due to excessive fat accumulation influences the immune function, but a lot of research has reported that an excessive accumulation of body fat will increase sensitivity to infectious diseases and affect their rising prevalence (Karlsson et al., 2010). Such research includes Martí et al. (2001), which reported a reduction of immunologic competence including the number of lymphocytes and natural killer (NK) cells after conducting an experiment with ob/ob mice in which obesity was artificially induced, and Macaulay et al. (2013), which reported that TNF- $\alpha$ deteriorated the function of T cells.
${ }^{*}$ Corresponding author: Joo Young Kim (iD https://orcid.org/0000-0003-4846-6259 School of Pharmaceutical Sciences, Ewha Womans University, 52 Ewhayeodae-gil, Seodaemun-gu, Seoul 03760, Korea

Tel: +82-2-3277-3016, Fax: +82-2-3277-3051, E-mail: jooyoungkim75@gmail.com Received: June 10, 2018 / Accepted: July 24, 2018
This is an Open Access article distributed under the terms of the Creative Commons Attribution Non-Commercial License (http://creativecommons.org/licenses/by-nc/4.0/) which permits unrestricted non-commercial use, distribution, and reproduction in any medium, provided the original work is properly cited. 
The importance of regular exercise was widely confirmed in various studies. As interest in health maintenance and enhancement has gradually spread among the population based on such studies, the size of the population participating in exercise programs continues to rise regardless of age (Belozo et al., 2018). NCEP-ATP III (National Cholesterol Education Program - Adult Treatment Panel III) reported that weight control should come first before treatment of the metabolic syndrome and that weight loss based on a combination of diet and exercise improved insulin sensitivity, blood glucose, dyslipidemia, and blood pressure (Grundy et al., 2004). This is because metabolic syndrome is included in most obesity diagnosis criteria; thus, weight control is recommended to improve obesity factors. As for the effects of exercise on immunity, it has been reported that regular exercise generally enhances the immune function with some differences according to intensity, duration, type, and amount of exercise (He et al., 2001). However, when one exercises temporarily with high intensity or exercises too much, he or she will reduce immune function and be easily exposed to infection (Jin et al., 2015; Lee et al., 2012).

This study suggests that fitness and exercise performance may be improved by providing aerobic training and/or resistance training to obese subjects for 8 weeks. In particular, the combined training of resistance and aerobic exercise is important for these changes, suggesting that the inflammatory response may be reduced.

\section{MATERIALS AND METHODS}

\section{Participants}

The participants included 20 obese adult men in their thirties that had no experience with drinking, smoking, and other medications, no prior record of regular exercise, and no special medical diseases. They were assessed for obesity diagnosis based on $\mathrm{BMI} \geq 26 \mathrm{~kg} / \mathrm{m}^{2}$, which is in the Asia-Pacific Guideline of WHO (World Health Organization, 2000) and were randomly assigned

Table 1. Physical characteristics of the participants

\begin{tabular}{lcc}
\hline Characteristic & AT group $(\mathrm{n}=9)$ & CT group $(\mathrm{n}=8)$ \\
\hline Age $(\mathrm{yr})$ & $35.11 \pm 2.93$ & $33.50 \pm 3.07$ \\
Height $(\mathrm{m})$ & $1.72 \pm 0.05$ & $1.71 \pm 0.05$ \\
Weight $(\mathrm{kg})$ & $86.99 \pm 8.55$ & $84.80 \pm 9.61$ \\
Body mass index $\left(\mathrm{kg} / \mathrm{m}^{2}\right)$ & $29.31 \pm 1.75$ & $29.06 \pm 2.73$ \\
Body fat $(\%)$ & $30.47 \pm 3.21$ & $28.56 \pm 2.90$
\end{tabular}

Values are presented as mean \pm standard deviation.

AT, aerobic training; CT, combined aerobic and resistance training to the aerobic training (AT) group or the combined aerobic and resistance training $(\mathrm{CT})$ group, each of which consisted of ten men. The final participants included nine in the AT group and eight in the CT group after the exclusion of three that did not finish the 8-week training program (Table 1). The selection process of participants and the experimental procedure were shown in Fig. 1. This study was approved by the Ethics Committee of Jungwon University (1044297-HR-201802-005-03).

\section{Measurement of fitness, body composition, and physical performance}

The basic test covered height, weight, BMI, \%body fat, maximal oxygen uptake $\left(\mathrm{VO}_{2 \max }\right)$, and one-repetition maximum (1RM). \%body fat was measured in bioelectrical impedance analysis with Inbody 330 (Biospace Co., Seoul, Korea). Maximal oxygen uptakes were measured in a graded exercise test on a Q65 treadmill (Quinton Co., Milwaukee, WI, USA) with Meta Max 3B (Cortex Co., Leipzig, Germany) according to the Bruce protocol (American College of Sports Medicine [ACSM], 2014). In or-

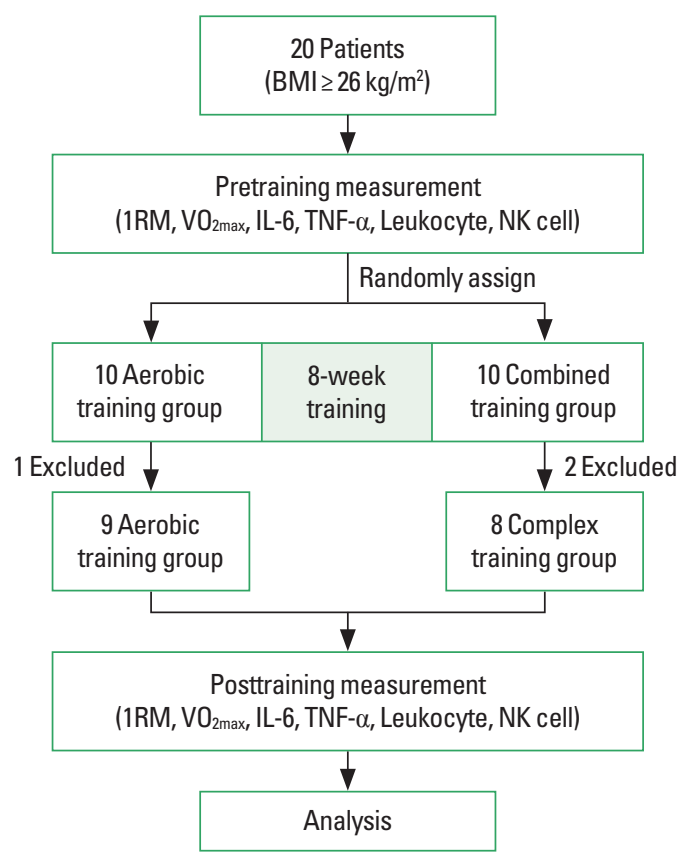

Fig. 1. A flow chart indicating participant's selection process and experimental procedure. Twenty participants $\left(\mathrm{BMl} \geq 26 \mathrm{~kg} / \mathrm{m}^{2}\right)$ were randomly assigned to the AT group $(n=10)$ and CT group $(n=10)$. During the 8-week training period, 3 participants disappeared (AT group, $n=9 ; C T$ group, $n=8$ ). Before and after training, basic tests were performed (1RM, VO 2max $_{1}, \mathrm{~L}-6$, TNF- $\alpha$, Leukocytes, NK cell). After all experiments were completed, the results were analyzed. BMI, body mass index; AT, aerobic training; CT, combined aerobic and resistance training; $1 \mathrm{RM}$, one-repetition maximum; $\mathrm{VO}_{2 \max }$, maximal oxygen uptake; IL, interleukin; TNF- $\alpha$, tumor necrosis factor-alpha; NK, natural killer. 
der to determine the maximum muscular strength in each part of the upper and lower body, 1RM of five sites were measured (bench press, lat pull down, arm curl, leg press, and squat machine) (Panatta Co., Apiro, Italy).

\section{Physical training program}

By consulting the guidelines of the American College of Sports Medicine, devised an 8-week training program consisting of 80min sessions (warm-up, $10 \mathrm{~min}$; main exercise, $60 \mathrm{~min}$; and cooldown, $10 \mathrm{~min}) 4$ times per week. The main exercises were organized according to the characteristics of each group. The main exercise of the AT group was designed to have the participants reach $70 \%$ maximal heart rate within $5 \mathrm{~min}$ from the start of the exercise by setting the treadmill inclination at $0 \%$ first and then increasing the speed gradually. The intensity of the exercises was maintained in the range of $\pm 5 \%$ with a wireless heart rate monitor (Polar Electro Co., Kempele, Finland). The target heart rate was set with Karvonen Formula based on the maximum heart rates measured in the basic test (Karvonen et al., 1957). The main exercise of the CT group consisted of $30 \mathrm{~min}$ of aerobic exercise at the same intensity as the AT group and weight training. Based on the $1 \mathrm{RM}$ of five sites measured in the basic test, a weight training session was implemented 4 times a week with an event done in two sets at the intensity of 10RM that was $70 \%$ of $1 \mathrm{RM}$. Time for resting between sets was limited to $1 \mathrm{~min}$ and $20 \mathrm{sec}$.

During the training period, the participants' diet was also controlled. The participants were recommended not to eat more than 2,400 kcal, which is the estimated daily energy intake for adults in the age range of 30-49 based on the nutritional intake criteria for Korean people. They also kept a meal log to manage their daily energy intake (Kim and Park, 2018).

\section{Blood sampling and analyses}

Before and after the 8-week training period, blood was collected with participants taking sufficient stability for more than one hour. Serums IL-6 and TNF- $\alpha$ were analyzed with the Quantikine human kit (R\&B Systems Inc., Minneapolis, MN, USA) through V-MAX 220V AC ELISA reader (Molecular Devices, Sunnyvale, CA, USA). The number of leukocytes was measured with STKS analyzer (Coulter Co., Miami, FL, USA), and \% NK cell was analyzed with BD FACSCanto Flowcytometer and BD FACSDiva software (BD Biosciences, Franklin Lakes, NJ, USA).

\section{Statistical analysis}

All data were presented as mean \pm standard deviation, and sta- tistical analysis was performed using GraphPad Prism version 7.02 (GraphPad Software, Inc., La Jolla, CA, USA) and SPSS ver. 17.0 (SPSS Inc., Chicago, IL, USA). Independent sample $t$-tests and paired sample $t$-tests were conducted to analyze differences between groups and among time points. In addition, Pearson correlation coefficient was calculated to determine whether serum TNF- $\alpha$ levels are related to \%body fat. All differences were considered significant at a $P$-value under 0.05 .

\section{RESULTS}

In this study, we investigated changes in body composition (weight, BMI, and \%body fat), physical performance (1RM in bench press and leg press, and $\mathrm{VO}_{2 \max }$, inflammatory markers (IL6 and TNF- $\alpha$ ), and immune markers (leukocyte and NK cell) as results of the 8 -week training program by exercise type in obese male participants.

Table 2 shows the results of the training programs regarding changes to the body composition and physical performance. As for weight changes, both the AT group $(P<0.05)$ and $\mathrm{CT}$ group $(P<$ 0.05 ) showed a significant decrease in body weight after the training. BMI was also significantly decreased after the training in both the AT group $(P<0.001)$ and the CT group $(P<0.05)$. Both the AT group $(P<0.001)$ and the CT group $(P<0.05)$ showed a significant decrease in their \%body fat after the training. As for changes to the physical performance, $1 \mathrm{RM}$ for bench press in the CT group was significantly increased after training $(P<0.05)$. Neither group showed significant differences in 1RM for leg press. Both the AT group $(P<0.05)$ and CT group $(P<0.05)$ showed signifi-

Table 2. Change of body composition and physical performance

\begin{tabular}{lccccc}
\hline \multirow{2}{*}{ Variable } & \multicolumn{2}{c}{ AT group $(\mathrm{n}=9)$} & & \multicolumn{2}{c}{ CT group $(\mathrm{n}=8)$} \\
\cline { 2 - 3 } \cline { 5 - 6 } & Pre & Post & & Pre & Post \\
\hline Body weight $(\mathrm{kg})$ & $86.99 \pm 8.55$ & $83.32 \pm 7.16^{*}$ & & $84.80 \pm 9.61$ & $81.61 \pm 8.29^{*}$ \\
$\begin{array}{c}\text { Body mass } \\
\text { index }\left(\mathrm{kg} / \mathrm{m}^{2}\right)\end{array}$ & $29.31 \pm 1.75$ & $28.09 \pm 1.53^{* *}$ & & $29.06 \pm 2.73$ & $27.99 \pm 2.45^{*}$ \\
Body fat $(\%)$ & $30.47 \pm 3.21$ & $28.17 \pm 3.15^{* *}$ & & $28.56 \pm 2.90$ & $26.56 \pm 2.44^{*}$ \\
Bench press $(\mathrm{kg})$ & $80.83 \pm 3.54$ & $81.11 \pm 4.17$ & & $77.81 \pm 4.11$ & $79.06 \pm 4.42^{*}$ \\
Leg press $(\mathrm{kg})$ & $276.25 \pm 20.66$ & $275.00 \pm 28.78$ & & $261.25 \pm 15.53$ & $262.50 \pm 15.81$ \\
VO $_{2 \max }$ & $34.07 \pm 3.10$ & $38.63 \pm 1.33^{*}$ & & $33.96 \pm 2.97$ & $37.35 \pm 3.10^{*}$ \\
$(\mathrm{~mL} / \mathrm{kg} / \mathrm{min})$ & & & & \\
\hline
\end{tabular}

Values are presented as mean \pm standard deviation.

AT, aerobic training; CT, combined aerobic and resistance training; Pre, measured before each training; Post, measured after each training; $\mathrm{VO}_{2 \max }$, maximal oxygen uptake.

${ }^{*}$ Significantly different from Pre-Tr $(P<0.05) .{ }^{* *}$ Significantly different from Pre-Tr $(P<0.001)$. 
Table 3. Change of inflammatory and immune markers

\begin{tabular}{lrrrrr}
\hline \multirow{2}{*}{ Variables } & \multicolumn{2}{c}{ ATGroup $(\mathrm{n}=9)$} & & \multicolumn{2}{c}{ CT Group $(\mathrm{n}=8)$} \\
\cline { 2 - 3 } \cline { 5 - 6 } & \multicolumn{1}{c}{ Pre } & \multicolumn{1}{c}{ Post } & & \multicolumn{1}{c}{ Pre } & Post \\
\hline IL-6 $(\mathrm{pg} / \mathrm{mL})$ & $0.72 \pm 0.14$ & $0.67 \pm 0.12$ & & $0.72 \pm 0.19$ & $0.71 \pm 0.15$ \\
TNF- $\alpha(\mathrm{pg} / \mathrm{mL})$ & $0.86 \pm 0.12$ & $0.80 \pm 0.14$ & & $0.84 \pm 0.17$ & $0.75 \pm 0.14^{*}$ \\
Leukocyte $\left(\times 10^{3} / \mathrm{\mu L}\right)$ & $6.51 \pm 2.19$ & $6.88 \pm 2.15$ & & $6.45 \pm 1.47$ & $6.78 \pm 2.01$ \\
NK-cell $^{\dagger}(\%)$ & $14.04 \pm 3.36$ & $14.83 \pm 4.20$ & & $15.80 \pm 0.67$ & $15.16 \pm 1.09$
\end{tabular}

Values are presented as mean \pm standard deviation.

AT, aerobic training; $C T$, combined aerobic and resistance training; Pre, measured before each training; Post, measured after each training; IL, interleukin; TNF- $\alpha$, tumor necrosis factor-alpha; NK, natural killer

${ }^{*}$ Significantly different from Pre $(P<0.05)$. ${ }^{\dagger}$ Percent relative to leukocytes.

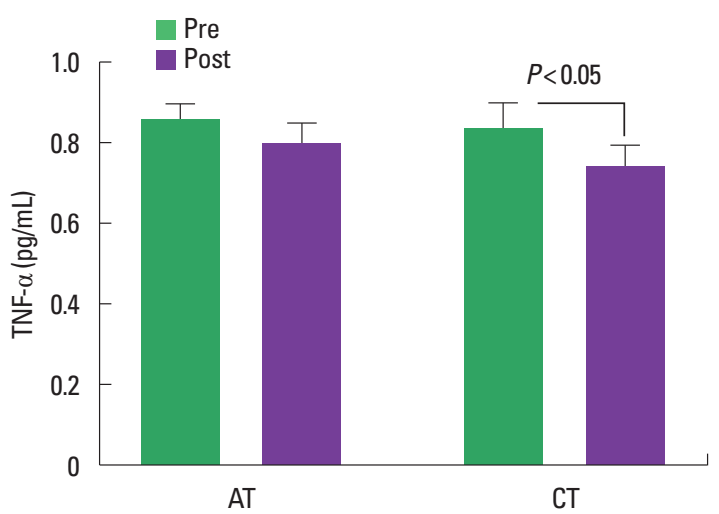

Fig. 2. Serum tumor necrosis factor-alpha (TNF- $\alpha$ ) levels before and after training. Each training program (AT or CT) was given to obese male participants for 8 weeks and TNF- $\alpha$ levels were measured in peripheral blood before and after each training. AT, aerobic training group; CT, combined aerobic and resistance training group; Pre, measured before each training; Post, measured after each training.

cantly enhanced maximum oxygen intake after the training.

Table 3 presents the results of the 8-week training program by exercise type regarding changes to inflammatory and immune markers. As for inflammatory marker changes, only the CT group showed significantly reduced serum TNF- $\alpha$ levels after the training $(P<0.05)$ (Fig. 2). In particular, the changes in the TNF- $a$ levels were correlated with \%body fat in the posttraining CT group (Fig. 3). Neither group showed statistical differences in blood IL-6 levels. As for immune marker changes, neither group had statistical differences in leukocytes and NK cells changes.

\section{DISCUSSION}

It has been reported that obesity causes an appearance issue of excessive fat accumulation and is also accompanied by many diseases including cardiovascular diseases, hypertension, metabolic
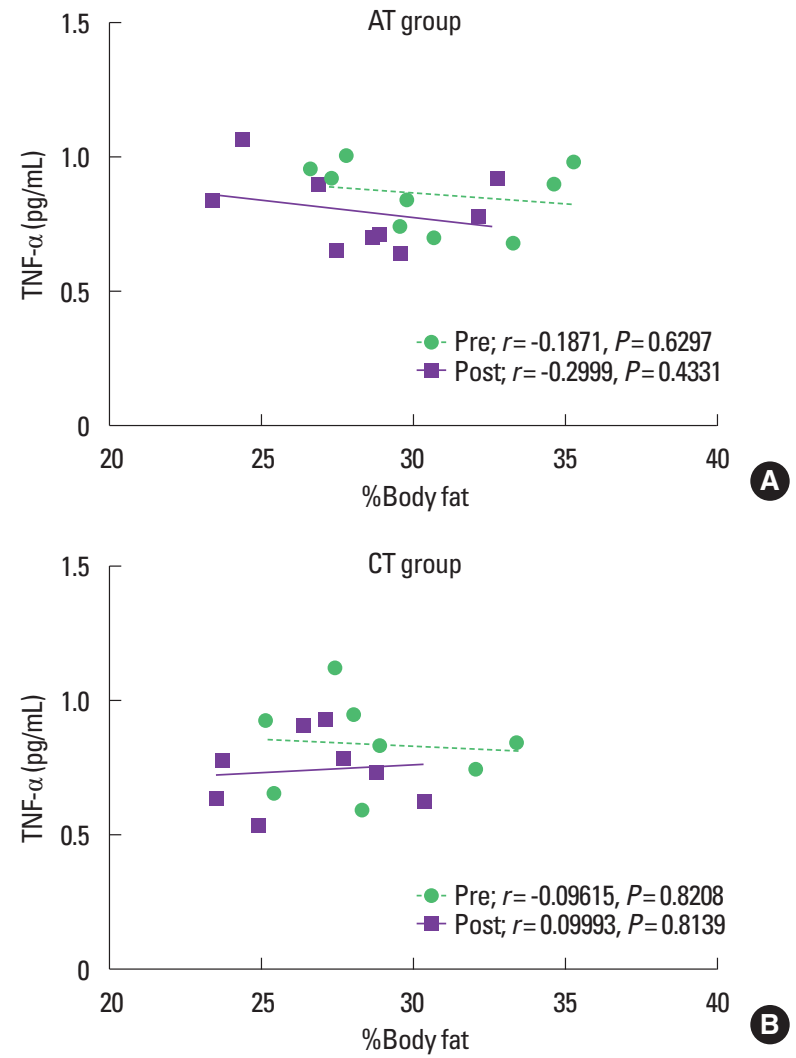

Fig. 3. Correlation between serum tumor necrosis factor-alpha (TNF- $\alpha$ ) levels and \%body fat before and after training. The correlation coefficient between TNF- $\alpha$ and \%body fat measured before and after training in AT group (A) and CT group (B) was measured. AT, aerobic training; CT, combined aerobic and resistance training; Pre, measured before each training; Post, measured after each training.

syndrome, sleep disorder, and physiological imbalance (Bhurosy and Jeewon, 2014). Much of the research conducted to improve the causes and risks of obesity have found that regular exercise is used as an essential method to treat obesity. Exercise has great effects on weight loss by reducing body fat and increasing lean body mass and is effective for follow-up management to have fewer side effects and maintains the effects of weight loss (Donnelly et al., 2004). It has been reported that walking and running, which have remarkable convenience and access, improve blood lipid metabolism abilities and is effective for preventing coronary artery and heart diseases. Researchers have recommended that resistance exercise should be combined with aerobic exercise since it increases basal metabolism, improves insulin reactions and prevents bone density loss (ACSM, 2014; Moon et al., 2018).

In the present study, we measured body weight, BMI and \%body fat to observe body composition changes after an 8-week 
training program by exercise type and found that both groups showed statistically significant differences. As for \%body fat changes, the AT group decreased by $2.30 \%$ after training and thus showed a little bit more changes than the CT group that decreased by $2.00 \%$, but there were no statistical differences between them. These findings are similar to those of previous studies reporting that combined training was a stable weight loss method in the long run based on \%body fat reduction and lean mass increase, but that aerobic training had the biggest effects on weight loss (ACSM, 2014; Yamamoto et al., 2008).

In the present study, we measured IL- 6 and TNF- $a$ levels in the peripheral blood to observe changes to inflammatory markers after the 8 -week training program by exercise type and found an overall reduction tendency in IL- 6 and TNF- $\alpha$, and statistically significant differences only in the TNF- $\alpha$ of the CT group. We also confirmed the correlation between the TNF- $\alpha$ and \%body fat in the posttraining CT group. These results matched those of previous studies reporting that the reduction of abdominal obesity through physical activities had positive impacts on inflammatory cytokines (Farinha et al., 2015; Koh and Park, 2017).

It has been reported that a leukocyte increase activates hemoconcentration and the adrenergic mechanism and thus causes the introduction of blood stored in the spleen, bone marrow, and liver into blood circulation and the increase of epinephrine with the leukocytes infiltration involved in this process (Delcenserie et al., 2008). NK cells as a lymphocytes subset apply their direct cytotoxic effects on tumor cells and the cells infected with a virus, thus serving as a powerful defense against virus infection (Koopman et al., 2003). The present study measured leukocytes and NK cells to observe changes to immune markers after the 8-week training program by exercise type and found that neither group had statistical differences in them. These results matched those of a previous study that administered aerobic exercise to obese men for 12 months and reported no significant differences in their leukocytes (Imayama et al., 2012) but did not agree with those of another previous study reporting that leukocytes increased in obese people after aerobic exercise (Johannsen et al., 2012).

In conclusion, the findings confirm a positive reduction in body composition (weight, BMI, and \%body fat) after an 8-week training program by exercise type and thus demonstrate that a combined training treatment is appropriate. The study also confirmed a significant reduction of TNF- $\alpha$ and correlation between the TNF- $\alpha$ levels and the \%body fat in the posttraining CT group. Finally, we found that restoring obesity through combined training of aerobic and resistance exercise is related to changes in serum TNF- $\alpha$ lev- els. We believe that our findings will provide a mechanism to explain the improvement of obesity through exercise.

\section{CONFLICT OF INTEREST}

No potential conflict of interest relevant to this article was reported.

\section{REFERENCES}

American College of Sports Medicine. ACSM's guidelines for exercise testing and prescription. 9th ed. Philadelphia (PA): Lippincott Williams \&Wilkins; 2014.

Belozo FL, Katashima CK, Cordeiro AV, Lenhare L, Alves JF, Silva VRR. Effects of ninety minutes per week of continuous aerobic exercise on blood pressure in hypertensive obese humans. J Exerc Rehabil 2018; 14:126-132.

Bhurosy T, Jeewon R. Overweight and obesity epidemic in developing countries: a problem with diet, physical activity, or socioeconomic status? ScientificWorldJournal 2014;2014:964236.

Delcenserie V, Martel D, Lamoureux M, Amiot J, Boutin Y, Roy D. Immunomodulatory effects of probiotics in the intestinal tract. Curr Issues Mol Biol 2008;10:37-54.

Donnelly JE, Smith B, Jacobsen DJ, Kirk E, Dubose K, Hyder M, Bailey B, Washburn $R$. The role of exercise for weight loss and maintenance. Best Pract Res Clin Gastroenterol 2004;18:1009-1029.

Farinha JB, Steckling FM, Stefanello ST, Cardoso MS, Nunes LS, Barcelos RP, Duarte T, Kretzmann NA, Mota CB, Bresciani G, Moresco RN, Duarte MM, Dos Santos DL, Soares FA. Response of oxidative stress and inflammatory biomarkers to a 12-week aerobic exercise training in women with metabolic syndrome. Sports Med Open 2015;1:19.

Goran MI. Energy metabolism and obesity. Med Clin North Am 2000;84: 347-362.

Grundy SM, Cleeman JI, Merz CN, Brewer HB Jr, Clark LT, Hunninghake DB, Pasternak RC, Smith SC Jr, Stone NJ; Coordinating Committee of the National Cholesterol Education Program. Implications of recent clinical trials for the National Cholesterol Education Program Adult Treatment Panel III Guidelines. J Am Coll Cardiol 2004;44:720-732.

He F, Tuomola E, Arvilommi H, Salminen S. Modulation of human humoral immune response through orally administered bovine colostrum. FEMS Immunol Med Microbiol 2001;31:93-96.

Imayama I, Ulrich CM, Alfano CM, Wang C, Xiao L, Wener MH, Campbell KL, Duggan C, Foster-Schubert KE, Kong A, Mason CE, Wang CY, Blackburn GL, Bain CE, Thompson HJ, McTiernan A. Effects of a caloric restriction weight loss diet and exercise on inflammatory bio- 
markers in overweight/obese postmenopausal women: a randomized controlled trial. Cancer Res 2012;72:2314-2326.

Jin CH, Paik IY, Kwak YS, Jee YS, Kim JY. Exhaustive submaximal endurance and resistance exercises induce temporary immunosuppression via physical and oxidative stress. J Exerc Rehabil 2015;11:198-203.

Johannsen NM, Swift DL, Johnson WD, Dixit VD, Earnest CP, Blair SN, Church TS. Effect of different doses of aerobic exercise on total white blood cell (WBC) and WBC subfraction number in postmenopausal women: results from DREW. PLoS One 2012;7:e31319.

Karlsson EA, Sheridan PA, Beck MA. Diet-induced obesity impairs the T cell memory response to influenza virus infection. J Immunol 2010; 184:3127-3133.

Karvonen MJ, Kentala E, Mustala O. The effects of training on heart rate; a longitudinal study. Ann Med Exp Biol Fenn 1957;35:307-315.

Kim JY, Sohn JH, Lee JH, Park JW. Obesity increases airway hyperresponsiveness via the TNF- $\alpha$ pathway and treating obesity induces recovery. PLoS One 2015;10:e0116540.

Kim KY, Park JS. Impact of fish consumption by subjects with prediabetes on the metabolic risk factors: using data in the 2015 (6th) Korea National Health and Nutrition Examination Surveys. Nutr Res Pract 2018;12: 233-242.

Koh Y, Park KS. Responses of inflammatory cytokines following moderate intensity walking exercise in overweight or obese individuals. J Exerc Rehabil 2017;13:472-476.
Koopman LA, Kopcow HD, Rybalov B, Boyson JE, Orange JS, Schatz F, Masch R, Lockwood CJ, Schachter AD, Park PJ, Strominger JL. Human decidual natural killer cells are a unique NK cell subset with immunomodulatory potential. J Exp Med 2003;198:1201-1212.

Lee YW, Shin KW, Paik IY, Jung WM, Cho SY, Choi ST, Kim HD, Kim JY. Immunological impact of Taekwondo competitions. Int J Sports Med 2012;33:58-66.

Macaulay R, Akbar AN, Henson SM. The role of the T cell in age-related inflammation. Age (Dordr) 2013;35:563-572.

Martí A, Marcos A, Martínez JA. Obesity and immune function relationships. Obes Rev 2001;2:131-140.

Moon DC, Kim MJ, Lee CM. Meta-analysis on the effect of combined exercise program intervention on Korean middle-aged women. J Exerc Rehabil 2018;14:394-398.

World Health Organization. Obesity and overweight [Internet]. Geneva: World Health Organization; c2017 [cited 2017 Oct 18]. Available from: http://www.who.int/en/news-room/fact-sheets/detail/obesity-andoverweight.

World Health Organization. The Asia-Pacific perspective: redefining obesity and its treatment. Geneva: World Health Organization; 2000.

Yamamoto LM, Lopez RM, Klau JF, Casa DJ, Kraemer WJ, Maresh CM. The effects of resistance training on endurance distance running performance among highly trained runners: a systematic review. J Strength Cond Res 2008;22:2036-2044. 